\title{
Mechanical Properties and Pore Structure Characteristics of Magnesium Oxychloride Cement Modified by Highland Barley Straw Ash
}

\section{Feng Cao}

Lanzhou University of Technology

Hongxia Qiao ( $\square$ qhxlut7706@163.com )

Lanzhou University of Technology

Penghui Wang

Lanzhou University of Technology

Weijia Li

Qinghai Nationalities University

\section{Research Article}

Keywords: Magnesium oxychloride cement, Highland barley straw ash, Mechanical properties, Pore structure, Microstructure

Posted Date: April 29th, 2021

DOI: https://doi.org/10.21203/rs.3.rs-462267/v1

License: (c) (i) This work is licensed under a Creative Commons Attribution 4.0 International License. Read Full License 


\title{
Mechanical Properties and Pore Structure Characteristics of Magnesium Oxychloride Cement
}

\section{Modified by Highland Barley Straw Ash}

\author{
Feng Cao ${ }^{1,2}$, Hongxia Qiao ${ }^{1,2, *}$, Penghui Wang ${ }^{1}$, Weijia Li $^{2}$
}

1. School of Civil Engineering, Lanzhou University of Technology, Lanzhou Gansu, China;

2. School of civil and transportation engineering, Qinghai Nationalities University, Xining Qinghai, China.

*Corresponding author: Hongxia Qiao, E-mail: qhxlut7706@163.com

Abstract: Highland barley straw ash contains a large amount of silica, and the ash calcined and ground under certain conditions has a higher pozzolanic effect. In order to study the effect of HBSA added into magnesium oxychloride cement mortar (MOCM) on the mechanical properties and pore structure, the activity of highland barley straw ash was studied firstly through the macroscopic mechanical properties test. Nuclear magnetic resonance (NMR) and Brunner-EmmetTeller (BET) were used to test the distribution of full pore and micropore for MOCM respectively. The microstructure of MOCM was characterized by scanning electron microscope (SEM). The results illustrate that the highest activity of HBSA was obtained by calcining at $600^{\circ} \mathrm{C}$ for $2 \mathrm{~h}$ and grinding for $2 \mathrm{~h}$. The addition of HBSA has a significant effect on the mechanical properties and pore diameter distribution of MOCM. A large amount of M-S-H gel was generated in MOCM added with $10 \%$ HBSA content, and had a consequence of decreased proportion of larger pores and the increased proportion of micropores as well as the better mechanical properties and pore structure.

Keywords: Magnesium oxychloride cement; Highland barley straw ash; Mechanical properties; Pore structure; Microstructure

\section{Introduction}

Magnesium oxychloride cement is a new type of ecological building material, which is mixed by $\mathrm{MgO} \mathrm{MgCl}_{2}$ and $\mathrm{H}_{2} \mathrm{O}$ in a certain proportion[1-3]. There is a wide application prospect in the engineering field due to the advantages as high early strength, good brine corrosion resistance, and good wear resistance, etc.[4,5]. However, the characteristics of poor water resistance and corroded steel bar limit its further application[6,7]. The main reason of poor water resistance is that 
the 5 and 3 phases of magnesium oxychloride cement products are unstable phases, which could be converted into bischofite under certain conditions and make the structure become loose and porous[8-10].

It has been found that rice husk ash[11-13], fly ash[14-16] and wheat straw ash[17,18], etc. can improve the pore structure and mechanical properties of magnesium oxychloride cement. It has been studied that adding rice husk ash into MOC might be able to obtain higher density and better mechanical properties, and reduce water absorption and improve durability[19]. According to Guo et al., the incorporation of $30 \%$ fly ash in MOC could optimize the pore structure, make the structure more compact, and significantly improve the mechanical properties and water resistance[20]. Recent research has suggested that the cement-based material mixed with $15 \%$ wheat straw ash has smaller porosity and higher mechanical properties[21]. Wang et al. hold the view that nano silica is beneficial to improve the early compressive strength of cement, and the addition of fly ash is beneficial to improve the late compressive strength. The synergistic effect of the nanomaterials and the active mineral admixture can optimize the volcanic ash effect, reduce the porosity and improve the pore structure [22]. Tan et al. found that silica fume could significantly improve the pore structure of basic magnesium sulfate cement and the proportion of gel pores and small pores might be increased by adding silica fume. M-S-H gel with talc structure was formed due to the secondary hydration reaction between silica fume and magnesium hydroxide, which facilitates the formation of interconnected and dense microstructure[23].

From the above researches, the findings from these studies suggest that the main reason why the admixtures above could be able to improve the pore structure and mechanical performance is that they all contain active silica. The reactive silica reacts with the hydration products of the cement-based material to form new products that densifies its pore structure[2427]. Similar to rice husk ash, fly ash and wheat straw ash, highland barley straw contains a large amount of ash, and the content of silica in the ash is high[28], which makes it possible to be used as cement-based auxiliary cementitious materials. However, these results would seem to suggest that there are few reports on the activity of highland barley straw ash and the effect of its incorporation into magnesium oxychloride cement on the mechanical properties and pore structure. 
Therefore, there is great of interest to study the effect of HBSA on the mechanical properties and pore structure of MOCM.

In this paper, the activity of highland barley straw ash (HBSA) was analyzed by mechanics performance testing. The HBSA was added into magnesium oxychloride cement mortar (MOCM) in different proportions, the effect on mechanical properties was studied. Its pore structure was analyzed and compared by NMR and BET. The microstructure of the MOCM was characterized and the influence mechanism was further revealed.

\section{Materials and Methods}

\subsection{Materials}

The raw materials of MOCM are composed largely of light burning magnesium oxide (MgO), industrial magnesium chloride $\left(\mathrm{MgCl}_{2} \cdot 6 \mathrm{H}_{2} \mathrm{O}\right)$, sand, water, a water reducing agent, and water reducer. Light burning magnesium oxide is produced by the Magnesium Chloride Plant of Qarhan Salt Lake in Golmud City, Qinghai Province. The amount of MgO is accounted for $98 \%$ of light burning magnesium oxide and the amount of active $\mathrm{MgO}$ is $62.4 \%$. The chemical composition is shown in Table 1. Industrial magnesium chloride is produced by Qarhan Salt Lake Magnesium Chloride Factory in Golmud City, Qinghai Province. $96 \%$ of the industrial magnesium chloride are $\mathrm{MgCl}_{2} \cdot 6 \mathrm{H}_{2} \mathrm{O}$, and its chemical composition is shown in Table 2. Sand with a particle size less than $4.75 \mathrm{~mm}$ was obtained from Guide River in Qinghai Province, it is graded well and adopts tap water mixing, which meets the requirements of the concrete mixing water standard. The water reducer adopts a UNF series high efficiency water reducer, with an efficiency of $21 \%$. The water repellent is phosphoric acid, which is produced by Shuangshuang Chemical Co., Ltd., Yantai City, Shandong Province. The proportion of $\mathrm{H}_{3} \mathrm{PO}_{4}$ is at least $85 \%$ in the water repellent, and the chromaticity Hc unit is at most $25 \%$ of that. The highland barley straw was obtained from the Nanmenxia area of Huzhu County, Qinghai Province. After weeds and other impurities were removed, it was burned to ash in an outdoor natural environment. The burning point is approximately $300^{\circ} \mathrm{C}$, and the burning time was approximately $3 \mathrm{~h}$. After soil, sand, gravel, and other impurities are removed, the ash from the burnt highland barley straw, the integrated SX2-12-10A intelligent box muffle furnace was used for secondary calcination under laboratory conditions. The calcination times were 2,5 , and $8 \mathrm{~h}$ at temperatures of 500,600 , and $700^{\circ} \mathrm{C}$, respectively. The second-calcined HBSA was ground in a roller ball mill for $0.5,1$, and $2 \mathrm{~h}$, respectively. $\mathrm{HBSA}$ was calcined at $500^{\circ} \mathrm{C}, 600^{\circ} \mathrm{C}$ and $700^{\circ} \mathrm{C}$ for $5 \mathrm{~h}$, respectively, and the chemical composition was measured by X-ray fluorescence method, as shown in Table 1.

Table 1 Chemical composition of HBSA at different calcination time of $600^{\circ} \mathrm{C}(\mathrm{wt} / \%)$ 


\begin{tabular}{cccccccccc}
\hline Temperature & $\mathrm{SiO}_{2}$ & $\mathrm{Na}_{2} \mathrm{O}$ & $\mathrm{MgO}$ & $\mathrm{Al}_{2} \mathrm{O}_{3}$ & $\mathrm{P}_{2} \mathrm{O}_{5}$ & $\mathrm{Fe}_{2} \mathrm{O}_{3}$ & $\mathrm{~K}_{2} \mathrm{O}$ & $\mathrm{GaO}$ & Other \\
\hline $500^{\circ} \mathrm{C}$ & 57.056 & 2.515 & 2.528 & 3.528 & 6.465 & 4.014 & 9.454 & 11.979 & 2.461 \\
$600^{\circ} \mathrm{C}$ & 61.434 & 2.393 & 2.095 & 5.942 & 5.899 & 3.851 & 5.335 & 10.542 & 2.509 \\
$700^{\circ} \mathrm{C}$ & 62.633 & 2.602 & 2.269 & 3.098 & 5.905 & 2.411 & 6.440 & 11.427 & 3.215 \\
\hline
\end{tabular}

\subsection{Specimen Preparation}

According to the previous research results [29], the mixture ratio of magnesium oxychloride cement mortar is shown in Table 2. To study the HBSA's activity, it was prepared under the following conditions: calcination temperatures $(500,600$, $\left.700^{\circ} \mathrm{C}\right)$; calcination time $(2,5,8 \mathrm{~h})$, and grinding time $(0.5,1,2 \mathrm{~h})$. According to the mass ratio of magnesium oxide, $15 \%$ HBSA was added directly into the MOC mortar mixture. When the mixture was stirred evenly, it was loaded into a $40 \mathrm{~mm} \times 40 \mathrm{~mm} \times 160 \mathrm{~mm}$ cast iron mold for casting, vibration, and compaction. Then, it was cured in the air and demolded after 24 hours, and continued to cure in the air until 28 days. Each group consisted of 3 pieces, with a total of 28 groups and 84 pieces. One group of specimens without HBSA were included. The specimens numbered HBSA-0-0-0 refer to MOCM specimens without incorporation of HBSA, and the specimen numbered HBSA-500-2-0.5 refers to the MOCM specimen containing HBSA after calcination for $2 \mathrm{~h}$ at $500^{\circ} \mathrm{C}$ and grinding for $0.5 \mathrm{~h}$, etc.

Table 2 The mixture ratio of MOCM added with HBSA $\left(\mathrm{kg} / \mathrm{m}^{3}\right)$

\begin{tabular}{cccccccc}
\hline $\mathrm{MgO}$ & $\mathrm{MgCl}_{2}$ & Sand & Water reducer & Water Repellent & Water & \multicolumn{2}{c}{ HBSA } \\
\hline & & & & 135.59 & $0 \%$ & 0 \\
& & & & 141.14 & $5 \%$ & 19.45 \\
388.96 & \multirow{2}{*}{147.81} & \multirow{2}{*}{625} & \multirow{2}{*}{16.02} & 4.58 & 146.69 & $10 \%$ & 38.90 \\
& & & & 152.24 & $15 \%$ & 58.34 \\
& & & & 157.79 & $20 \%$ & 77.79 \\
& & & & 168.79 & $30 \%$ & 116.69 \\
\hline
\end{tabular}

In order to study the effect of HBSA incorporation into MOCM on water resistance, HBSA which prepared under the highest activity conditions was added into MOCM admixture with the mass ratio of $0 \%, 5 \%, 10 \%, 15 \%, 20 \%$ and $30 \%$ of $\mathrm{MgO}$ respectively. HBSA was added into MOCM directly rather than the equal proportional replacement of MgO. MOCM specimens were prepared to test water resistance according to the ratio of raw materials in the mixture ratio in Table 1. The prism test blocks of $40 \mathrm{~mm} \times 40 \mathrm{~mm} \times 160 \mathrm{~mm}$ were also poured, with 3 pieces in each group, a total of 12 groups and 36 pieces. After curing under indoor natural conditions for $24 \mathrm{~h}$, the mold is removed and the natural curing is continued for 
$28 \mathrm{~d}$. Among them, 6 groups of specimens were cured for $28 \mathrm{~d}$ and then soaked in water for $28 \mathrm{~d}$ to make them fully hydrated.

\subsection{Test Methods}

\subsubsection{Mechanical Properties}

To study the HBSA's activity, 84 pieces of MOCM specimens added HBSA which prepared in 28 kinds of conditions were tested for mechanical properties. After curing naturally for $28 \mathrm{~d}$, the flexural and compressive strength tests were carried out on the specimens by using the Hualong cement mortar flexural and compressive testing machine. The prismatic specimen was tested for flexural strength firstly, and then the compressive strength was tested after breaking. Each group of test blocks' mean value was taken as the strength test result.

The MOCM was mixed with HBSA under the optimal preparation conditions. At each dosage, the flexural strength and compressive strength of one group of test blocks were tested after natural curing for $28 \mathrm{~d}$. The other one group of test blocks were soaked in water for 28 days and taken out. After wiping the water on the surface, the flexural strength and compressive strength were tested immediately. The softening coefficient $\varphi$ is calculated according to the following formula [30]:

$$
\varphi=\frac{f_{w}}{f_{d}}
$$

in which $\mathrm{f}_{\mathrm{w}}$ is the compressive strength of MOCM specimen after soaked in water for 28 days, and $\mathrm{f}_{\mathrm{d}}$ is the compressive strength of MOCM specimen after natural curing for $28 \mathrm{~d}$.

\subsubsection{Aperture Test}

NMR technology could measure the real pore size distribution in the sample more accurately because it does not destroy the pores during the testing process[31]. NMR technology are widely used to calculate the volume of pores in porous media by measuring the mass and density of water in the sample to obtain such parameters as porosity and pore size distribution. By testing the signal of an $\mathrm{H}$ atom in the sample, a greater number of $\mathrm{H}$ atoms indicates more water contained, i.e., the proportion of the pore is higher where water is under this signal[32]. A $40 \mathrm{~mm} \times 40 \mathrm{~mm} \times 40 \mathrm{~mm}$ cube block was intercepted from the MOCM specimen for NMR test, and the effective aperture testing range was $2 \mathrm{~nm} \sim 1 \mathrm{~mm}$. The pore size distribution could be calculated by the transverse relaxation time $\mathrm{T} 2$ distribution as follows[33]:

$$
\frac{1}{T_{2}}=\rho_{2} \frac{S}{V}
$$

in which $\mathrm{T}_{2}$ is the medium's transverse relaxation time, ms; $\mathrm{S}$ is the pore's surface area, $\mathrm{um}^{2} ; \mathrm{V}$ is the pore's volume, $\mathrm{um}^{3} ; \mathrm{p}_{2}$ is $\mathrm{T}_{2}$ 's surface relaxation ratio, $\mathrm{um} / \mathrm{ms}$.

\subsubsection{Micro Measurement}


An automatic BET specific surface area analyzer was used to test the micro-pore size distribution of MOCM. The effective pore diameter test range was $2 \mathrm{~nm} \sim 100 \mathrm{~nm}$, and the adsorption and desorption medium were nitrogen. The test sample is taken from the crushed block after the compressive strength test, and the length of the side is not more than $5 \mathrm{~mm}$. Field emission scanning electron microscopy (SEM) was used to test the micromorphology of MOCM samples. The test samples were taken from the flakes crushed by the compressive strength test, and the microcosmic scanning was carried out after gold spraying. The BET and SEM test samples were soaked in alcohol for $24 \mathrm{~h}$ before the test to terminate further hydration, and then taken out and dried before the test.

\section{Results and discussion}

\subsection{HBSA Activity}

From the chemical composition of HBSA, it can be seen that the content of silica is about $60 \%$, which is a potential pozzolan materials. The compressive strength test results of MOCM added with HBSA which prepared under the above 28 conditions, as shown in Fig.1. The calculated results of activity index are shown in Table 3. It can be seen that the compressive strength of $\mathrm{MOCM}$ with $\mathrm{HBSA}$ calcined at $600^{\circ} \mathrm{C}$ is higher than that of $500^{\circ} \mathrm{C}$ and $700^{\circ} \mathrm{C}$, and the compressive strength of MOCM at $700^{\circ} \mathrm{C}$ is the lowest. The results indicated that the activity calcined at $600^{\circ} \mathrm{C}$ was the highest, followed by that at $500^{\circ} \mathrm{C}$, and the activity calcined at $700^{\circ} \mathrm{C}$ was the lowest. When the calcination temperature is $500^{\circ} \mathrm{C}$ and $600{ }^{\circ} \mathrm{C}$, the compressive strength of MOCM is the highest calcined at $2 \mathrm{~h}$, followed by that at $5 \mathrm{~h}$ and the lowest calcined at $8 \mathrm{~h}$, indicating that the activity of HBSA is the highest calcined at $2 \mathrm{~h}$. While the calcination temperature is $700^{\circ} \mathrm{C}$, the compressive strength is the highest calcined at $8 \mathrm{~h}$, followed by that at $5 \mathrm{~h}$, and the lowest calcined at $2 \mathrm{~h}$. This is because that a large amount of $\mathrm{SiO}_{2}$ exists in the form of crystal calcined at $700^{\circ} \mathrm{C}$, and the content of active $\mathrm{SiO}_{2}$ is less. At this time, the particle filling effect of HBSA was mainly worked in MOCM, rather than the active effect. Therefore, when the calcination temperature is $700^{\circ} \mathrm{C}$, the longer the calcination time is, the more crystalline $\mathrm{SiO}_{2}$ content is, and the better the filling effect is. When the calcination temperature is $500^{\circ} \mathrm{C}, 600^{\circ} \mathrm{C}$ and $700^{\circ} \mathrm{C}$, and the calcination time is $2 \mathrm{~h}, 5 \mathrm{~h}$, and $8 \mathrm{~h}$, the compressive strength increases with the growth of the grinding time. The strength under $2 \mathrm{~h}$ of grinding time is the highest, followed by that for $1 \mathrm{~h}$ and the lowest grinding for $0.5 \mathrm{~h}$. The results indicate that the incorporation of HBSA after grinding for 2 hours into MOCM could effectively improve its activity and filling effect. The compressive strength of MOCM without HBSA is $49.7 \mathrm{MPa}$ after curing for $28 \mathrm{~d}$, while the compressive strength of MOCM with $15 \%$ HBSA content 
calcined at $600{ }^{\circ} \mathrm{C}$ for $2 \mathrm{~h}$ and ground for $2 \mathrm{~h}$ is $51.2 \mathrm{MPa}$ and the activity index reach to 1.03 . According to the test results of macroscopic mechanical properties, the activity effect of prepared HBSA is the highest when the calcination temperature is $600^{\circ} \mathrm{C}$, the calcination time is $2 \mathrm{~h}$, and the grinding time is $2 \mathrm{~h}$.
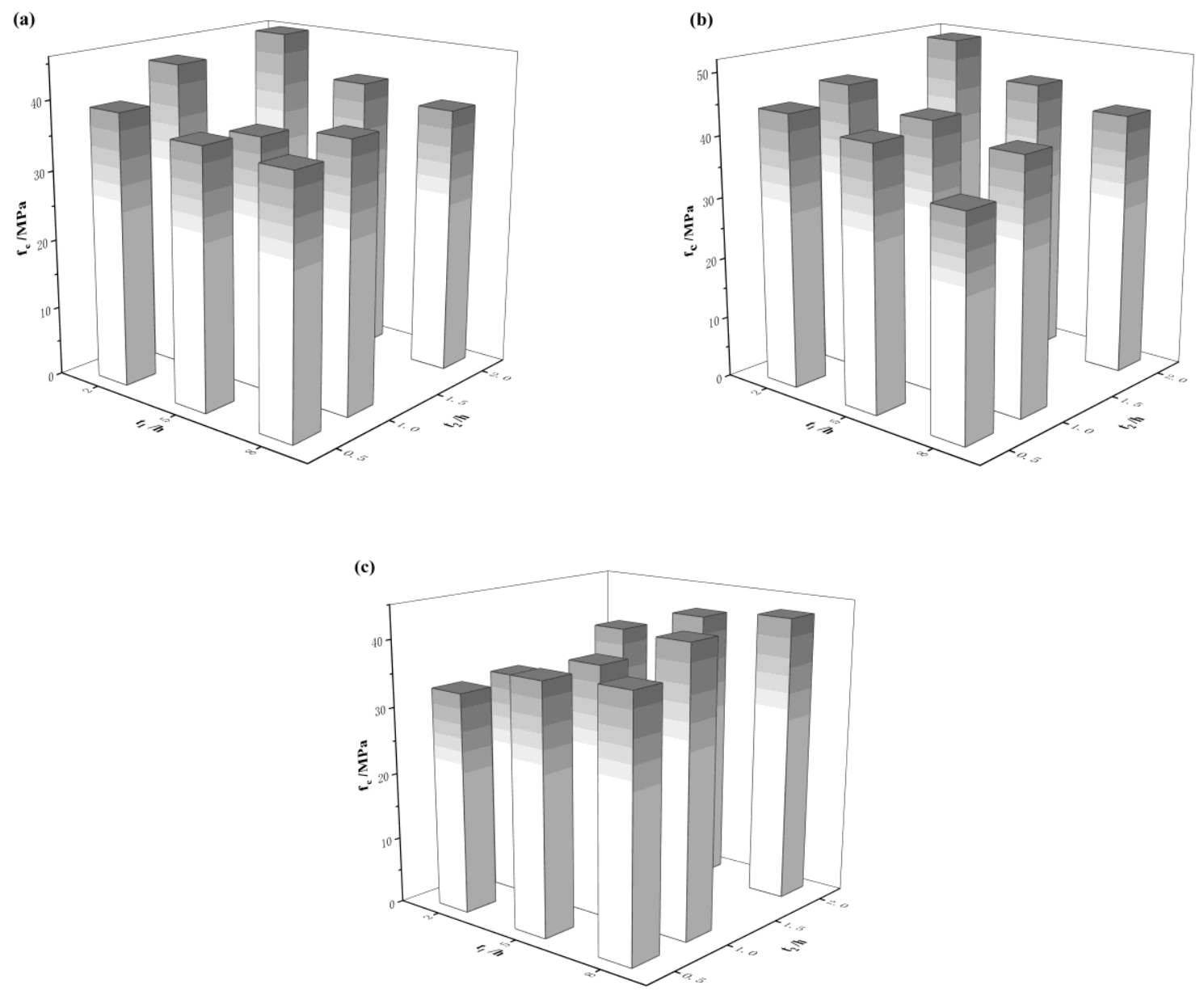

Fig. 1 Compressive strength of MOCM mixed with HBSA under different conditions (a) $500^{\circ} \mathrm{C}$; (b) $600^{\circ} \mathrm{C}$; (c) $700^{\circ} \mathrm{C}$ ( $f_{c}$ is the compressive strength; $t_{1}$ is Calcination time; $t_{2}$ is grinding time)

Table 3 Activity index of MOCM mixed with HBSA under different conditions

\begin{tabular}{cccccc}
\hline No. & Specimen number & Activity index & No. & Specimen number & Activity index \\
\hline 1 & HBSA-0-0-0 & 1.00 & 15 & HBSA-600-5-1 & 0.88 \\
2 & HBSA-500-2-0.5 & 0.79 & 16 & HBSA-600-5-2 & 0.92 \\
3 & HBSA-500-2-1 & 0.89 & 17 & HBSA-600-8-0.5 & 0.72 \\
4 & HBSA-500-2-2 & 0.92 & 18 & HBSA-600-8-1 & 0.83 \\
5 & HBSA-500-5-0.5 & 0.74 & 19 & HBSA-600-8-2 & 0.86 \\
6 & HBSA-500-5-1 & 0.73 & 20 & HBSA-700-2-0.5 & 0.67
\end{tabular}




$\begin{array}{lccccc}7 & \text { HBSA-500-5-2 } & 0.81 & 21 & \text { HBSA-700-2-1 } & 0.68 \\ 8 & \text { HBSA-500-8-0.5 } & 0.73 & 22 & \text { HBSA-700-2-2 } & 0.76 \\ 9 & \text { HBSA-500-8-1 } & 0.77 & 23 & \text { HBSA-700-5-0.5 } & 0.75 \\ 10 & \text { HBSA-500-8-2 } & 0.77 & 24 & \text { HBSA-700-5-1 } & 0.75 \\ 11 & \text { HBSA-600-2-0.5 } & 0.90 & 25 & \text { HBSA-700-5-2 } & 0.83 \\ 12 & \text { HBSA-600-2-1 } & 0.95 & 26 & \text { HBSA-700-8-0.5 } & 0.77 \\ 13 & \text { HBSA-600-2-2 } & 1.03 & 27 & \text { HBSA-700-8-1 } & 0.86 \\ 14 & \text { HBSA-600-5-0.5 } & 0.86 & 28 & \text { HBSA-700-8-2 } & 0.86\end{array}$

\subsection{Mechanical Properties of MOCM}

The HBSA obtained by calcining at $600^{\circ} \mathrm{C}$ for $2 \mathrm{~h}$ and grinding for $2 \mathrm{~h}$ was added into MOCM with $0 \%, 5 \%, 10 \%$, $15 \%, 20 \%$, and $30 \%$ content, respectively. The specimens with natural curing for $28 \mathrm{~d}$ and soaking in water for $28 \mathrm{~d}$ were tested for flexural strength and compressive strength, respectively, and the results were shown in Fig.2. As can be seen from Fig.2 (a), the trend of the compressive strength under dry and saturated conditions both increased firstly and then reduced with the increase of HBSA content. When the content of HBSA was 5\%, the compressive strength was both the highest in dry and saturated conditions. The compressive strength in dry state increased by $26.56 \%$ and that in saturated state increased by $28.57 \%$ compared with that without HBSA. When the content of HBSA was less than $10 \%$, the compressive strength was higher in dry and saturated conditions. When the HBSA content was more than $15 \%$, the compressive strength under saturated condition was lower than that without HBSA. It can be seen from Fig.2(b), with the increase of HBSA content, the softening coefficient of MOCM increased firstly and then decreased. When the HBSA content was $10 \%$, the softening coefficient was the largest, which rose by $6.80 \%$ compared with that without HBSA. Therefore, MOCM has the best water resistance with the 10\% HBSA content. When the HBSA content was less than 10\%, the water resistance was enhanced to a certain extent. When the content of HBSA was more than $15 \%$, the softening coefficient decreased with the increase of the content of HBSA, and was all lower than that without HBSA. In conclusion, the addition of HBSA into MOCM could effectively improve the mechanical properties, but too much HBSA content is likely to decrease it. The optimum content of HBSA for improving the compressive strength and the water resistance might be $5 \%$ and $10 \%$, respectively. 

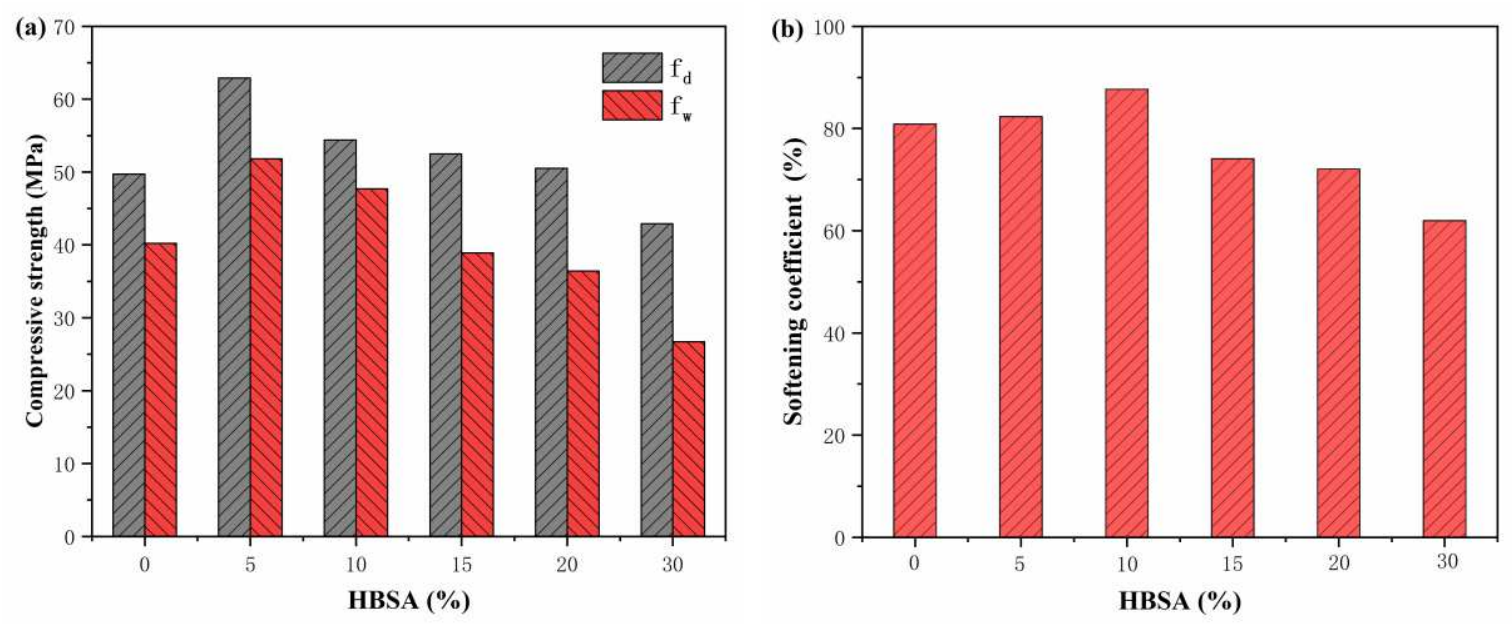

Fig.2 Mechanical properties of MOCM with different HBSA content (a)compressive strength;(b) softening coefficient

\subsection{Pore Structure Characteristics}

\subsubsection{NMR Analysis}

Fig. 3 shows the pore diameter distribution of MOCM specimens with HBSA content of $0 \%, 5 \%$ and $10 \%$ respectively by NMR test. The pore diameter distribution curves under the three content of HBSA are composed of three peaks. The first peak mainly represents the change of micro pores less than $0.2 \mathrm{um}$, the second peak represents small pores of $0.2 \mathrm{um}$ 10um, and the third peak represents large pores larger than 10um. The pore diameter distribution of MOCM is mainly concentrated in the micropores less than $0.2 \mathrm{um}$, as well as some small pores and large pores. With the increase of HBSA content, the pore diameter distribution of micro pores changes obviously, and the first peak moved to the left. It shows that new micropores are formed with the increase of HBSA content, and the most probable aperture becomes smaller and the proportion is higher. When the HBSA content was $5 \%$ and $10 \%$, the most probable aperture was smaller and the number of micropores less than $0.02 \mathrm{um}$ was more than that of without HBSA. It can be seen from the second peak that the pore diameter of MOCM specimens with 10\% HBSA content are concentrated in the small pore range less than those with HBSA content of $0 \%$ and $5 \%$. As shown from the third peak, the most probable aperture of MOCM specimen with HBSA content of $10 \%$ is less than that with HBSA content of $0 \%$ and $5 \%$. When the HBSA content increases to $10 \%$, the most probable aperture is the smallest, forming more and more new small-size pore, and the proportion of micropores was the highest. 


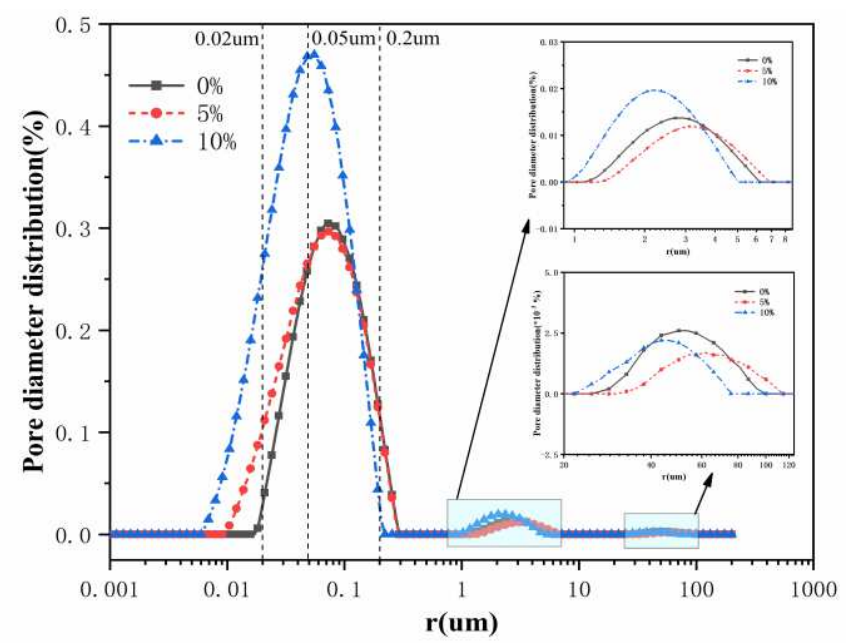

Fig.3 The pore diameter distribution of MOCM with different HBSA content

The statistics of pore diameter distribution in each interval of MOCM specimens with different HBSA content are shown in Table 4. Wang et al. set up the division of pore diameter interval[22]. It can be seen from Table 3, the proportion of the harmless pores and the less harmful pores whose diameter is less than 0.05 um increases gradually, while the proportion of the harmful pores and the more harmful pores whose diameter is more than $0.05 \mathrm{um}$ decrease by degrees with the increase of HBSA content. When the HBSA content was 10\%, the proportion of harmful pores and more harmful pores decreased by $25.11 \%$ compared with that without HBSA, and the reduced pores were transformed into harmless pores and less harmful pores. The number of harmless pores less than $0.02 \mathrm{um}$ increased by 3.71 times, and the number of less harmful pores increased by 1.65 times. It indicates that HBSA added in MOCM could transform part of harmful and more harmful pores into harmless and less harmful pores, which make the pore structure more favorable.

Table 4 The pore diameter distribution statistics of MOCM with different HBSA content (\%)

\begin{tabular}{ccccc}
\hline HBSA content & $<20 \mathrm{~nm}$ & $20 \sim 50 \mathrm{~nm}$ & $50 \sim 200 \mathrm{~nm}$ & $>200 \mathrm{~nm}$ \\
\hline $0 \%$ & 3.78 & 22.69 & 66.52 & 7.01 \\
$5 \%$ & 6.06 & 29.46 & 58.84 & 5.64 \\
$10 \%$ & 14.04 & 37.54 & 46.06 & 2.36 \\
\hline
\end{tabular}

\subsubsection{BET Analysis}

According to the pore diameter distribution results of NMR test, most of the pore in MOCM are concentrated in the pores below $100 \mathrm{~nm}$. For the furthering study of the pore diameter distribution within the range of 100nm, BET was used to test the mesopore structure of MOCM. The adsorption and desorption isotherms are the basis for analyzing the specific surface area and pore diameter distribution of MOCM[34,35]. MOCM's adsorption and desorption 
isotherms with different HBSA content were obtained by nitrogen adsorption method, as shown in Fig.4. The MOCM's adsorption and desorption isotherms with the three HBSA content are basically the same, including initial, transition and end segment. At the initial segment, the slope of the curve gradually increases with the grow of HBSA content, which illustrates that the number of micropores in MOCM gradually increases[36]. Then, the adsorption and desorption isotherm are separated at transition segment. When the HBSA content increases to $10 \%$, the relative pressure value corresponding to the separation point is the smallest, which demonstrates that the internal pore diameter is the smallest. The adsorption and desorption isotherms overlap again at the end segment. The curve slope of the adsorption and desorption isotherm of MOCM with 5\% and 10\% HBSA content was higher than that with $0 \%$ HBSA content at the end segment.
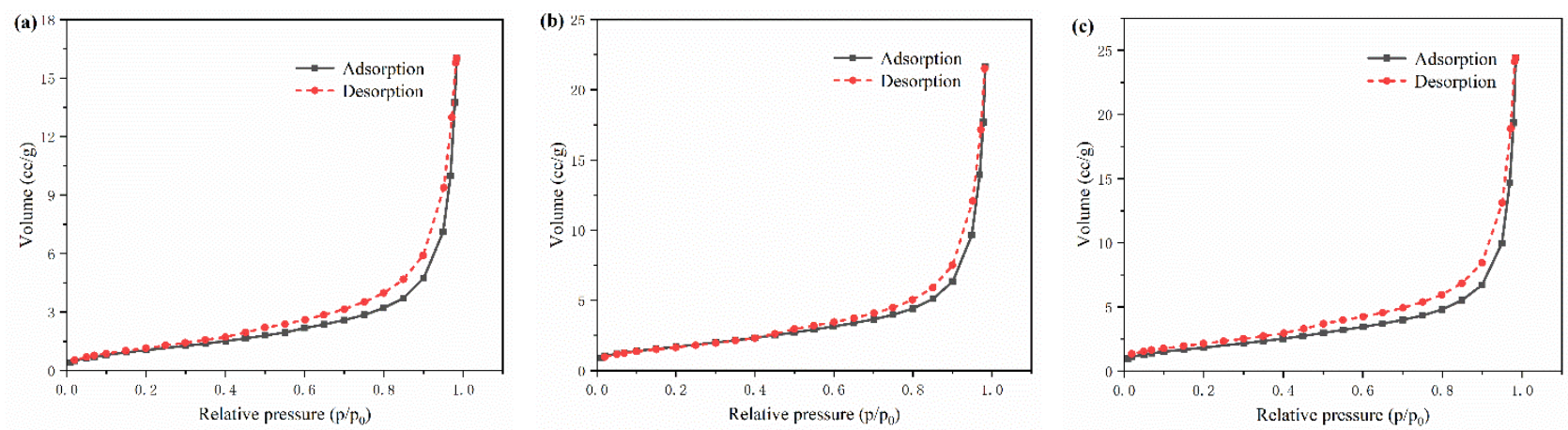

Fig.4 Adsorption and desorption isotherms of MOCM specimens with different HBSA content(a) $0 \%$;(b)5\%;(c)10\%

The specific surface area of MOCM was obtained by BET multi-point test. The data points in the coordinate were linearly fitted to obtain the multi-point BET two-bit linear graph[37], as shown in Fig.5. The slope and intercept of the twobit line were obtained by linear fitting. According to the BET test principle[38,39], the area of each milliliter of nitrogen molecules diffused into a monolayer is $4.354 \mathrm{~m}^{2}$. The specific surface area obtained through the BET method is shown in Table 5. It can be seen that the specific surface area of MOCM gradually increases with the rise of HBSA content, indicating that the number of micro pores inside MOCM increases correspondingly. When HBSA content was $10 \%$, the specific surface area increased by $32.75 \%$ compared with that without HBSA, and the increased specific surface area was caused by the increase of internal micropores. Therefore, these results suggest that the addition of HBSA could form a part of micropores in MOCM, and the number of micropores is the largest when the HBSA content is $10 \%$. 


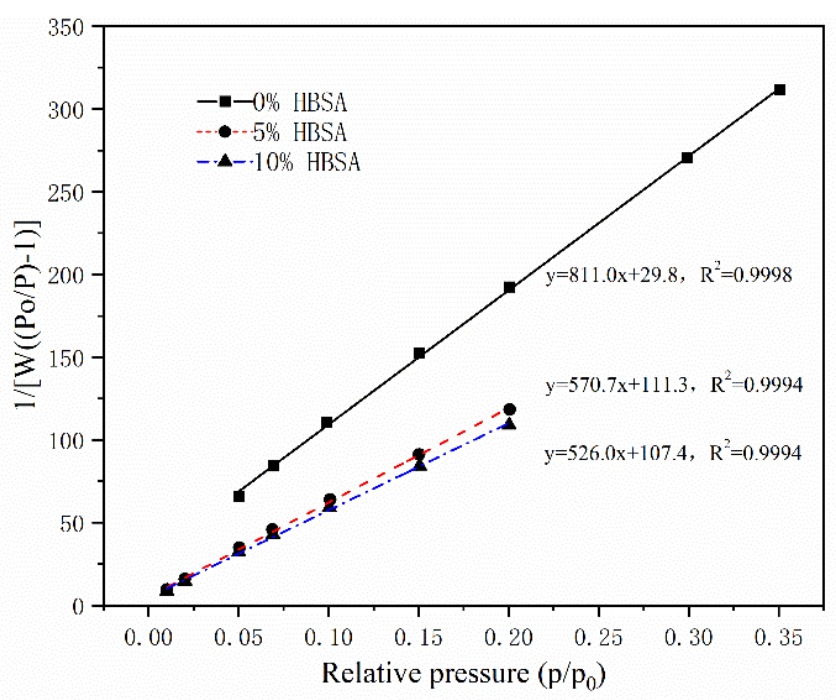

Fig.5 Multi-point BET fitting two-bit line graph

Table 5 Specific surface area of MOCM with different HBSA content

\begin{tabular}{ccccc}
\hline HBSA content & Slope $(\mathrm{k})$ & Intercept $(\mathrm{b})$ & $\mathrm{V}_{\mathrm{m}}=1 /(\mathrm{k}+\mathrm{b})$ & $\begin{array}{c}\text { Surface area } \\
\left(4.354 * \mathrm{Vm}, \mathrm{m}^{2} / \mathrm{g}\right)\end{array}$ \\
\hline $0 \%$ & 811.0 & 29.8 & 0.0012 & 5.178 \\
$5 \%$ & 570.7 & 111.3 & 0.0014 & 6.384 \\
$10 \%$ & 526.0 & 107.4 & 0.0016 & 6.874
\end{tabular}

The distribution of pores diameter through the BET method is shown in Fig.6. As can be seen from Figure 6(a) and (b), the variation rule of pore diameter distribution of MOCM with different HBSA content is basically the same, but the pore diameter proportion of MOCM with different HBSA content and the most probable aperture are obviously different. When the HBSA content is $10 \%$, the most probable aperture is $3.730 \mathrm{~nm}$ in the micropores range less than $20 \mathrm{~nm}$, and it is less than $3.831 \mathrm{~nm}$ and $3.836 \mathrm{~nm}$ when the HBSA content was $5 \%$ and $0 \%$, respectively. The most probable aperture is $54.929 \mathrm{~nm}$ in the mesoporous range of $20 \mathrm{~nm}-100 \mathrm{~nm}$, which is less than $76.302 \mathrm{~nm}$ and $77.459 \mathrm{~nm}$ when the HBSA content is $5 \%$ and $0 \%$, respectively. It can be seen that when the HBSA content is $5 \%$ and $10 \%$, the growth rate of cumulative pore volume is significantly faster than that HBSA content is $0 \%$. A possible explanation for these results may be that MOCM with the HBSA content of 5\% and $10 \%$ generated more micropores. 

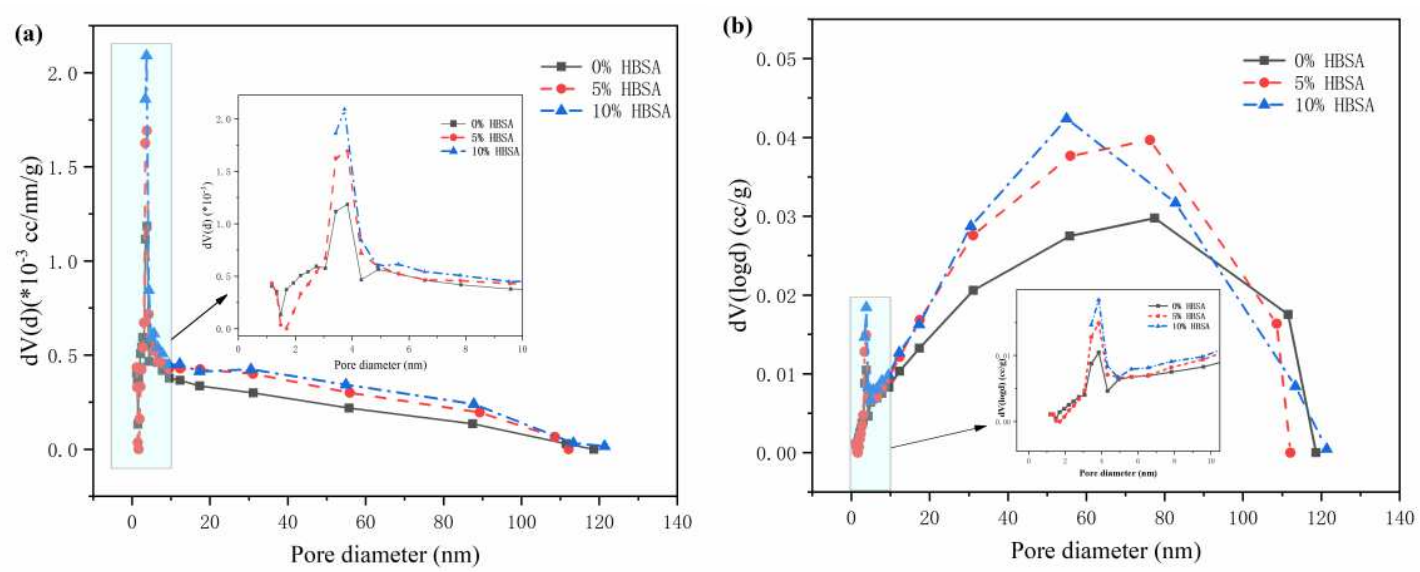

Fig.6 Pore diameter distribution of MOCM with different HBSA content(a)micropores;(b) mesoporous

The variation relationship of MOCM's pore volume and surface area with different HBSA content is shown in Fig.7.

It can be seen that MOCM's micropores with 5\% HBSA content have the largest cumulative volume, while MOCM's micropores with $10 \%$ HBSA content have the largest cumulative specific surface area. However, the cumulative volume of MOCM's micropores with HBSA content of $10 \%$ was less than that with HBSA content of $5 \%$. Large surface area and small volume indicate a greater number of micropores and a smaller pore diameter. MOCM with HBSA content of $0 \%$ had the smallest proportion of micropores. In addition, it can be seen from the fig. 3 that when the HBSA content was $5 \%$ and $10 \%$, the cumulative pore volume growth rate was significantly faster than that when the HBSA content was $0 \%$, indicating that MOCM with the HBSA content of $5 \%$ and $10 \%$ generated more micropores. The pore volume and surface area basically do not increase when the pore size is around $90 \mathrm{~nm}$, because the effective test pore size range of BET is within $100 \mathrm{~nm}$.
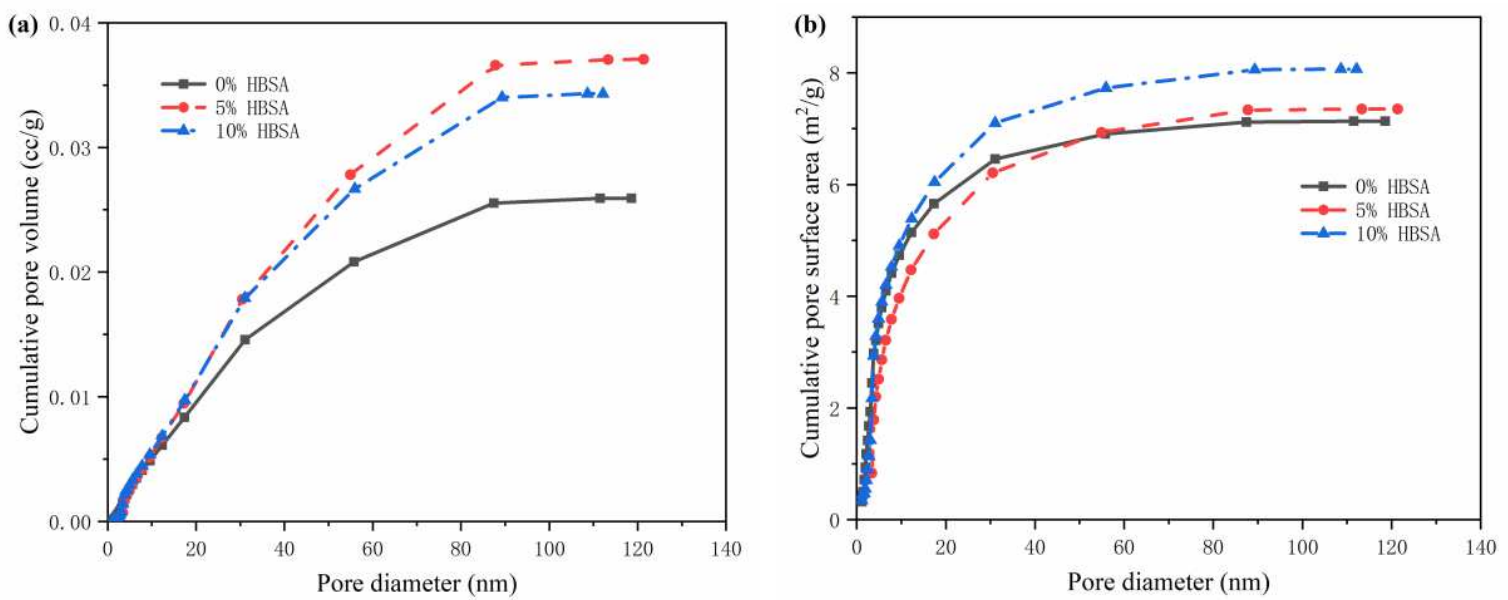
Fig.7 MOCM with different HBSA content for (a)cumulative pore volume; (b)cumulative pore surface area

\subsection{Microstructure}

The microtopography of MOCM samples with HBSA content of $0 \%, 5 \%$ and $10 \%$ are shown in Fig.8 (a), (b) and (c). When the HBSA content is $0 \%$, the micromorphology of MOCM is mainly composed of 5-phase needle-like crystal and a small amount of M-S-H gel. When the HBSA content is 5\% and 10\%, the micromorphology shows that a lot of M-S-H gel is generated. The M-S-H gel generated in the MOCM with 10\% HBSA content, which adhere uniformly to the 5-phase crystal and solid particle surface, filling a large number of crystal gaps and solid particle gaps, and eventually form in a more compact structure. When the HBSA content is $10 \%$, the 5-phase crystal of needle-like is uniformly wrapped by MS-H gel, forming the copolymer of needle-like crystal and gel. Some of the larger pores are transformed into micro pores due to the filling of the gel. This plays a positive and effective role in the pore diameter distribution of the pore structure, which is consistent with the results of NMR and BET test. Therefore, the fundamental reason for the change of pore structure is that the active silica in HBSA reacts with the hydration product from MOCM in a secondary hydration reaction to generate M-S-H gel. Some larger pores are filled with gel, forming a denser structure. In this work, HBSA was directly added into $\mathrm{MCOM}$ without replacing $\mathrm{MgO}$, so that the molar ratio of $\mathrm{MgO}$ to $\mathrm{MgCl} 2$ remained unchanged at 6.25. Under the condition of magnesium surplus, hydration products are mainly 5-phase and magnesium hydroxide[40]. The basic process of hydration reaction is as follows:

The first hydration process: $5 \mathrm{MgO}+\mathrm{MgCl}_{2} \cdot 6 \mathrm{H}_{2} \mathrm{O}+3 \mathrm{H}_{2} \mathrm{O} \rightarrow 5 \mathrm{Mg}(\mathrm{OH})_{2} \cdot \mathrm{MgCl}_{2} \cdot 8 \mathrm{H}_{2} \mathrm{O}$

$$
\mathrm{MgO}+\mathrm{H}_{2} \mathrm{O} \rightarrow \mathrm{Mg}(\mathrm{OH})_{2}
$$

The second hydration process: $3 \mathrm{Mg}(\mathrm{OH})_{2}+2 \mathrm{SiO}_{2} \rightarrow \mathrm{Mg}_{3} \mathrm{Si}_{2} \mathrm{O}_{5}(\mathrm{OH})_{4}+\mathrm{H}_{2} \mathrm{O}$ (Serpentine)

$$
\begin{aligned}
3 \mathrm{Mg}(\mathrm{OH})_{2}+4 \mathrm{SiO}_{2} & \rightarrow \mathrm{Mg}_{3} \mathrm{Si}_{4} \mathrm{O}_{10}(\mathrm{OH})_{2}+2 \mathrm{H}_{2} \mathrm{O} \text { (Talcum) } \\
8 \mathrm{Mg}(\mathrm{OH})_{2}+12 \mathrm{SiO}_{2}+8 \mathrm{H}_{2} \mathrm{O} & \rightarrow \mathrm{Mg}_{8}\left(\mathrm{H}_{2} \mathrm{O}\right)_{4}\left(\mathrm{Si}_{16} \mathrm{O}_{16}\right)_{2}(\mathrm{OH})_{4} \cdot 8 \mathrm{H}_{2} \mathrm{O} \text { (Sepiolite) }
\end{aligned}
$$

During the secondary hydration reaction, the values of $\mathrm{x}$ and $\mathrm{y}$ determine the structural form of $\mathrm{M}-\mathrm{S}-\mathrm{H}$. The general M-S-H structure mainly includes sepiolite, talcum and serpentine[26,41]. When the content of HBSA is $10 \%$, and the content of $\mathrm{SiO}_{2}$ in $\mathrm{HBSA}$ is about $60 \%$, that is, the $\mathrm{Mg} / \mathrm{Si}$ molar ratio is about 1.0 . At this point, after the hydration reaction of 28 days, there was almost no residual silica and brucite in the hydration products, and all reacted to form M-S-H gel [42]. The main structural forms of M-S-H gel are talc and serpentine, forming layered silicate structure, which adheres to the surface of 5-phase crystal and solid particles. Therefore, the mass generation of $\mathrm{M}-\mathrm{S}-\mathrm{H}$ improves the mechanical properties of MOCM and optimizes the pore structure. 
(a)

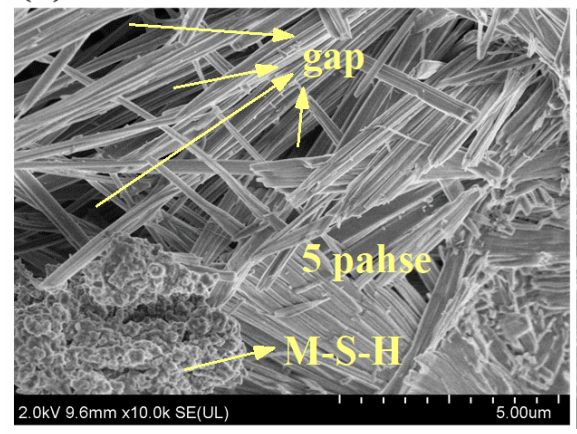

(b)

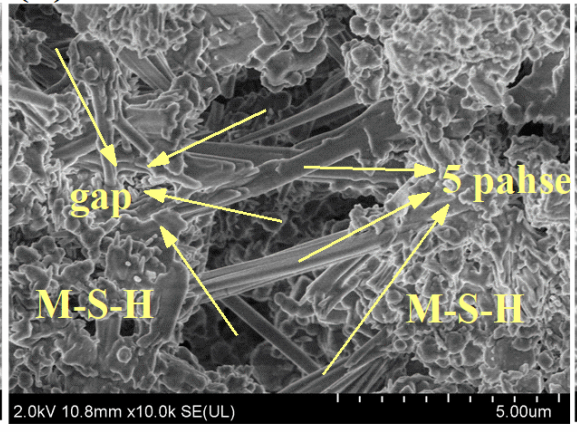

(c)

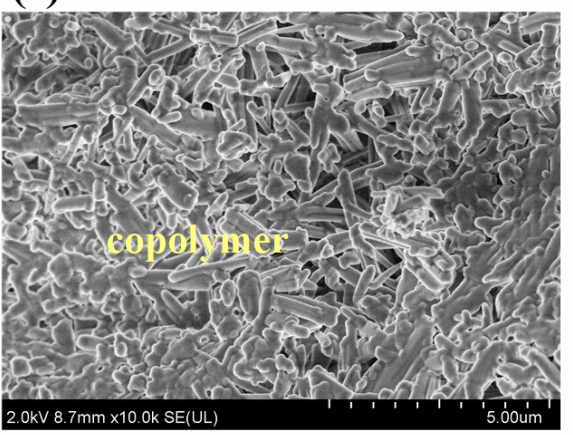

Fig. 8 SEM of MOCM with different HBSA content (a) $0 \%$;(b) $5 \%$;(c) $10 \%$

\section{Conclusion}

(1) The activity effect of HBSA obtained from highland barley straw is the highest after primary incineration of ash, secondary calcination at $600^{\circ} \mathrm{C}$ for $2 \mathrm{~h}$ and grinding for $2 \mathrm{~h}$.

(2) The addition of HBSA into magnesium oxychloride cement mortar could significantly improve its mechanical properties. When MOCM is added with 5\% HBSA, the compressive strength in dry state increases by $26.56 \%$ and that in saturated state increases by $28.57 \%$. When the HBSA content increases to $10 \%$, the water resistance of MOCM increases by $6.80 \%$.

(3) The pore structure of MOCM is significantly different with different HBSA content, and the incorporation of HBSA make the proportion of micropores in MOCM higher and the pore diameter smaller. When the HBSA content is $10 \%$, the number of harmful and more harmful pores decreases by $25.11 \%$ compared with that without HBSA. The number of harmless pores increases by 3.71 times, and the number of less harmful pores increases by 1.65 times. With the increase of HBSA content, the specific surface area of MOCM rises, and the most probable aperture decreases.

(4) The active silica in HBSA reacts with the hydration product of MOCM to form M-S-H gel, which fills part of the pores. Thus, some larger pores are transformed into smaller gel pores, and improve the pore structure. When the HBSA content is $10 \%$, the most M-S-H is generated and the pore structure is the best.

\section{Author Declarations}


Ethics approval and consent to participate Not applicable.

Consent for publication Not applicable.

Availability of data and materials All data generated or analyzed during this study are included in this published article.

Competing interests The authors declare that they have no competing interests.

Funding This work was financially supported by the National Natural Science Foundation of China (Nos. 51468039, 51868044). Authors appreciate the financial and equipment supports.

Authors' contributions Feng Cao-Investigation, Methodology, Writing - original draft, Writing - review \& editing.

Hongxia Qiao- Supervision, Writing -review \& editing. Penghui Wang- Writing - review \& editing. Weijia LiWriting - review \& editing.

Acknowledgements We appreciated Chongyan Qian and Jiaju Feng for their contribution in providing and collecting the raw materials of highland barley straw for this study.

\section{Compliance with Ethical Standards}

Disclosure of potential conflicts of interest The authors declare that they have no known competing financial interests or personal relationships that could have appeared to influence the work reported in this paper.

Research involving Human Participants and/or Animals Not applicable.

Informed consent Not applicable.

\section{References}

1. Li K, Wang Y, Yao N et al (2020) Recent progress of magnesium oxychloride cement: Manufacture, curing, structure and performance. Construction and Building Materials 255. DOI: 10.1016/j.conbuildmat.2020.119381

2. Huang Q, Li Y, Chang C, Wen J et al (2020) The Salt Attack Performance of Magnesium Oxychloride Cement Exposure 
to Three Kinds of Brines. Journal of Wuhan University of Technology-Mater. Sci. Ed. 35(20):155-166.

3. Wang F, Yang L, Guan L et al (2015) Microstructure and properties of cement foams prepared by magnesium oxychloride cement[J]. Journal of Wuhan University of Technology-Mater. Sci. Ed. 30(2):331-337.

4. Zhang X, Ge S, Wang H et al (2017) Effect of 5-phase seed crystal on the mechanical properties and microstructure of magnesium oxychloride cement. Construction and Building Materials 150: 409-417.

5. Chang C, Dong J, Xiao X et al (2019) Long-term mechanical properties and micro mechanism of magnesium oxychloride cement concrete. Advances in Cement Research:1-21. DOI: 10.1680/jadcr.18.00174

6. Wen J, Yu H, Li Y et al (2014) Effects of citric acid on hydration process and mechanical properties of thermal decomposed magnesium oxychloride cement. Journal of Wuhan University of Technology-Mater. Sci. Ed. 29(1):114118.

7. Tan Y, Liu Y, Grover L et al (2014) Effect of phosphoric acid on the properties of magnesium oxychloride cement as a biomaterial. Cement and Concrete Research 56:69-74.

8. Ye Q, Wang W, Zhang W et al (2018) Tuning the phase structure and mechanical performance of magnesium oxychloride cements by curing temperature and $\mathrm{H} 2 \mathrm{O} / \mathrm{MgCl} 2$ ratio. Construction and Building Materials 179:413-419.

9. Luo X, Fan W, Li C et al (2020) Effect of hydroxyacetic acid on the water resistance of magnesium oxychloride cement. Construction and Building Materials 246. 10.1016/j.conbuildmat.2020.118428

10. Huang T, Yu C, Yuan Q et al (2020) Effect of alcohol leachable chloride on strength of magnesium oxychloride cement. Journal of the American Ceramic Society 103(10):5927-5938.

11. Rattanachu P, Toolkasikorn P, Tangchirapat W et al (2020) Performance of recycled aggregate concrete with rice husk ash as cement binder. Cement and Concrete Composites 108. DOI: 10.1016/j.cemconcomp.2020.103533

12. Bheel N, Keerio M, Kumar A et al (2021) An Investigation on Fresh and Hardened Properties of Concrete Blended with Rice Husk Ash as Cementitious Ingredient and Coal Bottom Ash as Sand Replacement Material. Silicon :1-12. 
DOI: $10.1007 / \mathrm{S} 12633-020-00906-3$

13. Paul Venyite P, Makone E, Kaze R et al (2021) Effect of Combined Metakaolin and Basalt Powder Additions to LateriteBased Geopolymers Activated by Rice Husk Ash (RHA)/NaOH Solution. Silicon:1-20. DOI: 10.1007/S12633-02100950-7

14. Wu J, Chen H, Guan B et al (2019) Effect of Fly Ash on Rheological Properties of Magnesium Oxychloride Cement. Journal of Materials in Civil Engineering 31(3). DOI: 10.1061/(ASCE)MT.1943-5533.0002597

15. Li C, Yu H (2010) Influence of fly ash and silica fume on water-resistant property of magnesium oxychloride cement. Journal of Wuhan University of Technology-Mater. Sci. Ed. 25(4):721-724.

16. Sajjad Ali Mangi S, Ibrahim M, Jamaluddin N et al (2020) Establishment of Strength Prediction Equation for Concrete Containing Coal Bottom Ash Exposed to Aggressive Environment. Silicon: 1-13. DOI: 10.1007/s12633-020-00675-z

17. Qudoos A, Kakar E, Rehman A et al (2020) Influence of Milling Techniques on the Performance of Wheat Straw Ash in Cement Composites. Applied Sciences 10(10). DOI: 10.3390/app10103511

18. Jawad A, Faisal T, Fahid A et al (2021) A Step towards Sustainable Self-Compacting Concrete by Using Partial Substitution of Wheat Straw Ash and Bentonite Clay Instead of Cement. Sustainability 13(2):824-824.

19. Gomes C.M, Garry A.L, Freitas E et al (2020) Effects of Rice Husk Silica on microstructure and mechanical properties of Magnesium-oxychloride Fiber Cement (MOFC). Construction and Building Materials 241. DOI: $10.1016 /$ j.conbuildmat.2020.118022

20. Guo Y, Zhang Y, Soe K et al (2020) Effect of fly ash on mechanical properties of magnesium oxychloride cement under water attack. Structural Concrete 21(3):1181-1199.

21. Amin M.N, Murtaza T, Shahzada K et al (2019) Pozzolanic potential and mechanical performance of wheat straw ash incorporated sustainable concrete. Sustainability 11(2). DOI: $10.3390 /$ su11020519

22. Wang J, Liu M, Wang Y et al (2020) Synergistic effects of nano-silica and fly ash on properties of cement-based 
composites. Construction and Building Materials 262. DOI: 10.1016/J.CONBUILDMAT.2020.120737

23. Tan Y, Yu H, Sun S et al (2021) Properties and microstructure of basic magnesium sulfate cement: Influence of silica fume. Construction and building materials 266. DOI: 10.1016/J.CONBUILDMAT.2020.121076

24. Wu C, Zhang H, Yu H (2013) The effects of alumina-leached coal fly ash residue on magnesium oxychloride cement. Advances in Cement Research 25(5):254-261.

25. Zhang T, Zou J, Wang B et al (2018) Characterization of Magnesium Silicate Hydrate (MSH) Gel Formed by Reacting MgO and Silica Fume. Materials (Basel, Switzerland) 11(6). DOI: 10.3390/ma11060909

26. Ellina B, Barbara L, Christophe C et al (2019) Characterization of magnesium silicate hydrate (M-S-H). Cement and Concrete Research 116:309-330.

27. Li C, Yu H (2010) Influence of Fly Ash and Silica Fume on Water-resistant Property of Magnesium Oxychloride Cement. Journal of Wuhan University of Technology-Mater. Sci. Ed. 25(04):721-724.

28. Li S (2019) Mechanical properties of highland barley straw fiber reinforced mortar composites. Building Materials and Decoration 27:49-50. (in Chinese)

29. Wang P, Qiao H, Zhang Y et al (2020) Meso-damage evolution analysis of magnesium oxychloride cement concrete based on X-CT and grey-level co-occurrence matrix. Construction and Building Materials 255. DOI: 10.1016/j.conbuildmat.2020.119373

30. Li T, Huang F, Li L et al (2020) Preparation and properties of sulphoaluminate cement-based foamed concrete with high performance. Construction and Building Materials 263. DOI: 10.1016/j.conbuildmat.2020.120945

31. Wang Y, Yuan Q, Deng D et al (2017) Measuring the pore structure of cement asphalt mortar by nuclear magnetic resonance. Construction and Building Materials 137:450-458.

32. Valori A, McDonald P.J, Scrivener K.L (2013) The morphology of C - S - H: Lessons from $1 \mathrm{H}$ nuclear magnetic resonance relaxometry. Cement and Concrete Research 49:65-81.

33.Zhang J, Bian F, Zhang Y et al (2018) Effect of pore structures on gas permeability and chloride diffusivity of concrete. 
Construction and Building Materials 163:402-413.

34. Tu W, Liu Y, Xie Z et al (2021) A novel activation-hydrochar via hydrothermal carbonization and KOH activation of sewage sludge and coconut shell for biomass wastes: Preparation, characterization and adsorption properties. Journal of Colloid and Interface Science 593:390-407.

35. Li T, Huang Z, Zhao J et al (2021) Pore structure characteristics and their influencing factors: A case study from the middle jurassic mixed siliciclastic carbonate rocks, Turpan-Hami basin, Northwest China. Journal of Petroleum Science and Engineering 203. DOI: 10.1016/J.PETROL.2021.108611

36. Xie W, Xia J, Yu L et al (2021) Porous Multiphase Micro characteristics Research of New Cement-Based Grouting Material Concretion. Advances in Civil Engineering,2021.

37. Ji J, Dong Y, Zhang R et al (2021) Effect of Water Absorption and Loss Characteristics of Fine Aggregates on Aggregate-Asphalt Adhesion. KSCE Journal of Civil Engineering:1-16.

38. Gu L, Lv Q, Wang S et al (2021) Effect of sodium silicate on the properties of loess stabilized with alkali-activated fly ash-based. Construction and Building Materials 280. DOI: 10.1016/J.CONBUILDMAT.2021.122515

39. Xie J, Zhang H, Duan L et al (2020) Effect of nano metakaolin on compressive strength of recycled concrete. Construction and Building Materials 256. DOI: 10.1016/j.conbuildmat.2020.119393

40. Guo Y, Zhang Y, Soe K et al (2018) Recent development in magnesium oxychloride cement. Structural Concrete, 19(5):1290-1300.

41. Roosz C, Grangeon S, Blanc P et al (2015) Crystal structure of magnesium silicate hydrates (M-S-H): The relation with 2:1 Mg-Si phyllosilicates. Cement and Concrete Research 73:228-237.

42. Tonelli M, Martini F, Calucci L et al (2016) Structural characterization of magnesium silicate hydrate: towards the design of eco-sustainable cements. Dalton Transactions 45(8):3294-304. 
Figures

(a)

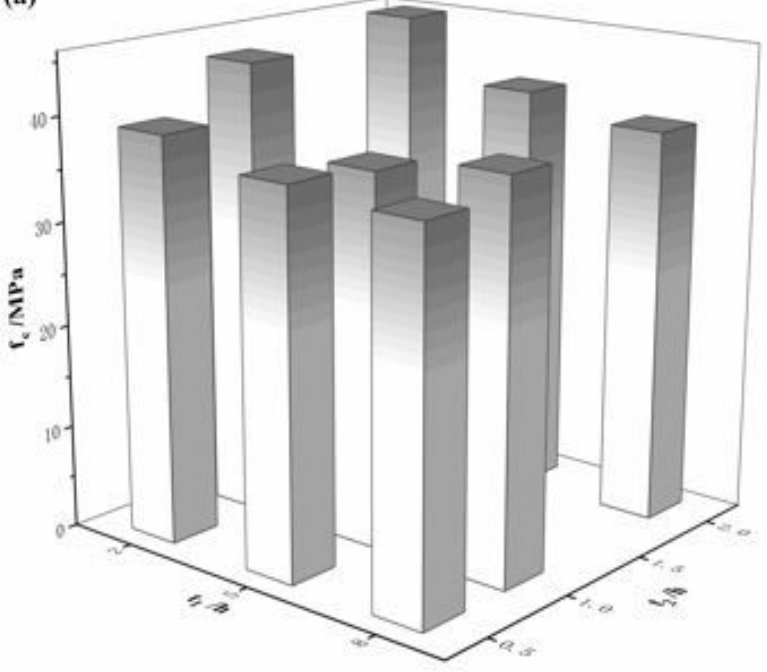

(b)

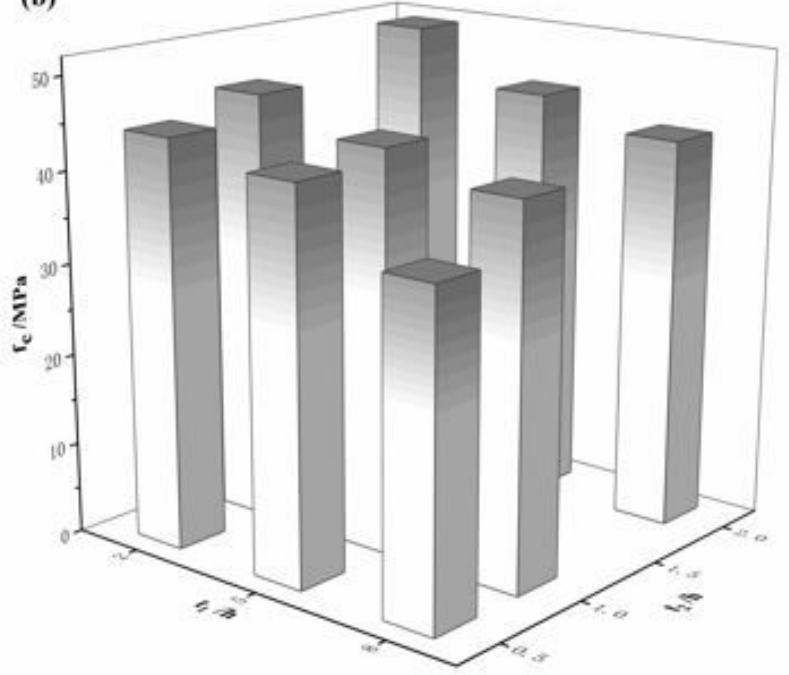

(c)

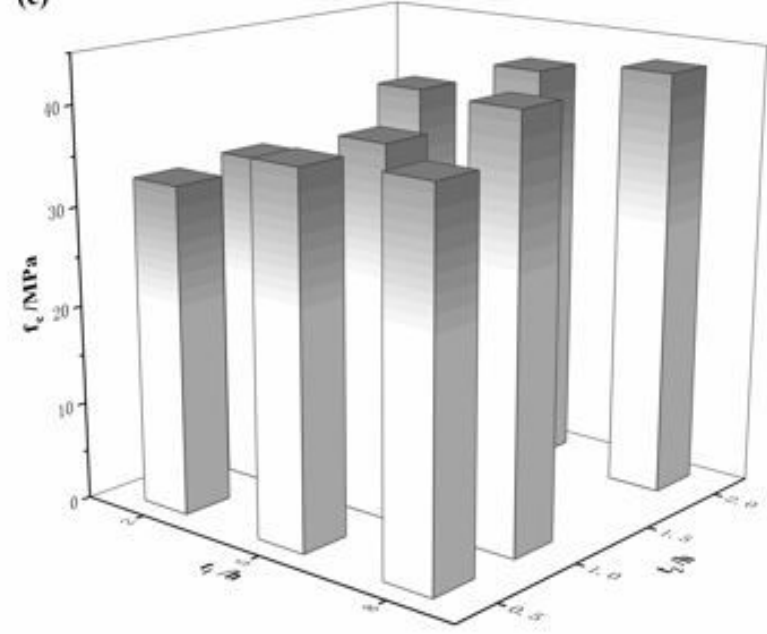

Figure 1

Compressive strength of MOCM mixed with HBSA under different conditions (a) 500》; (b) 600》; (c) 700》 ( $\mathrm{fc}$ is the compressive strength; $\mathrm{t} 1$ is Calcination time; $\mathrm{t} 2$ is grinding time) 

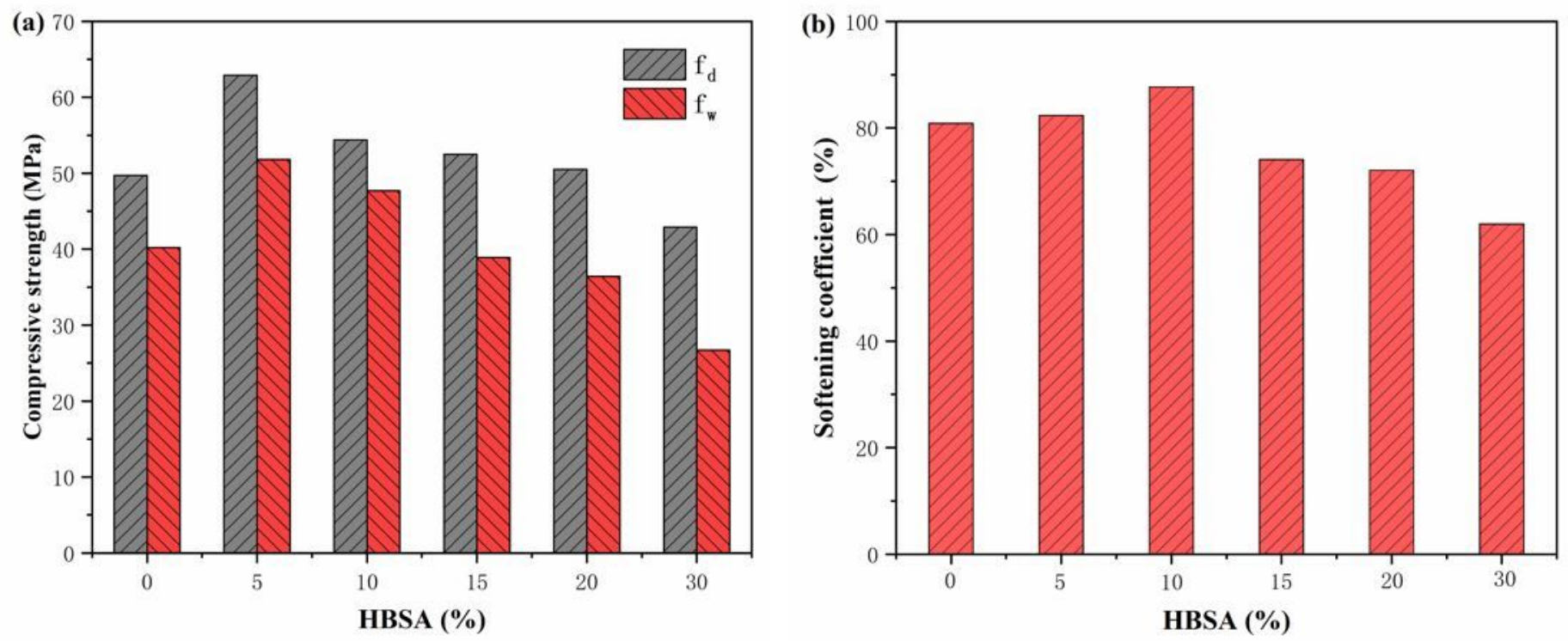

Figure 2

Mechanical properties of MOCM with different HBSA content (a)compressive strength;(b) softening coefficient

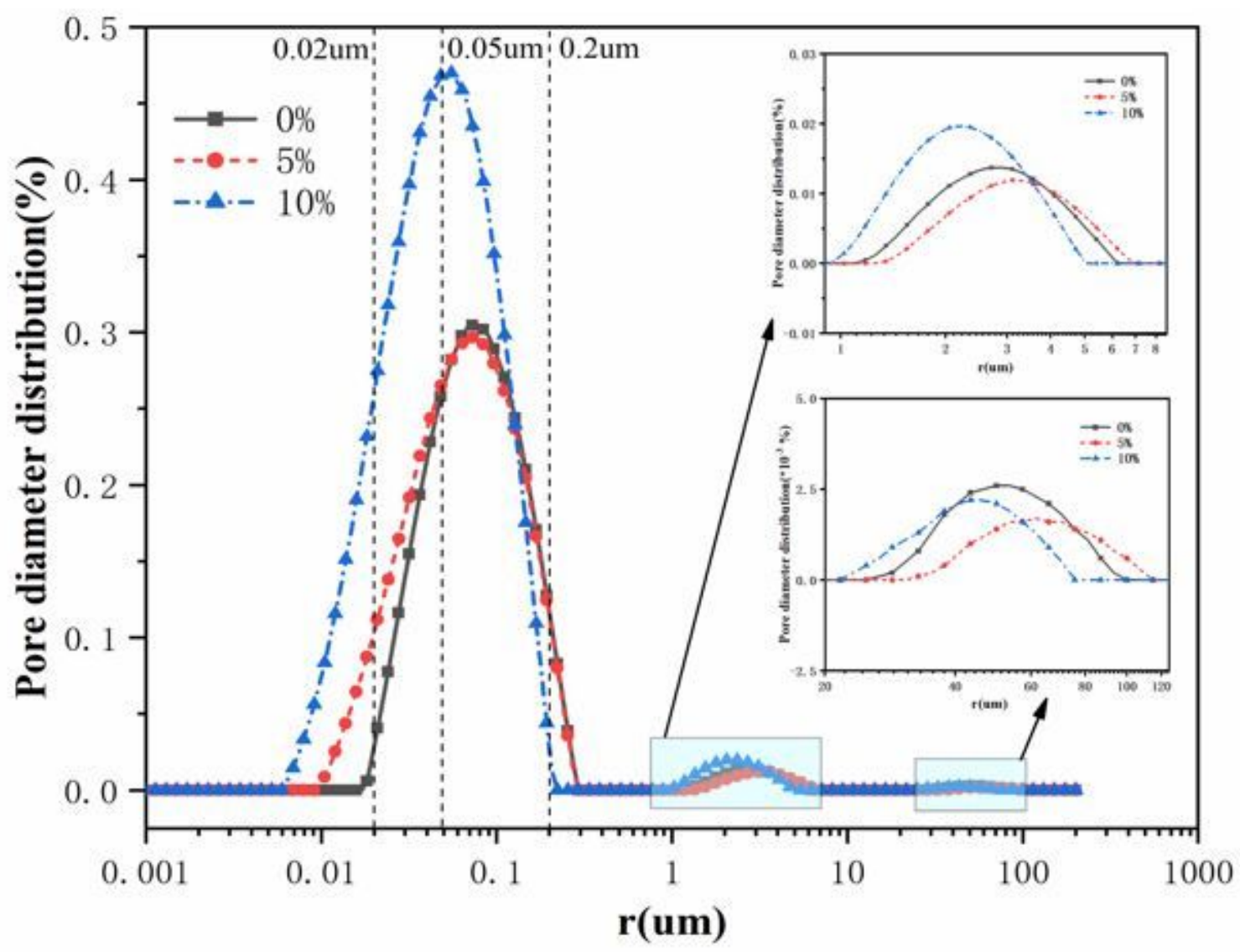


Figure 3

The pore diameter distribution of MOCM with different HBSA content
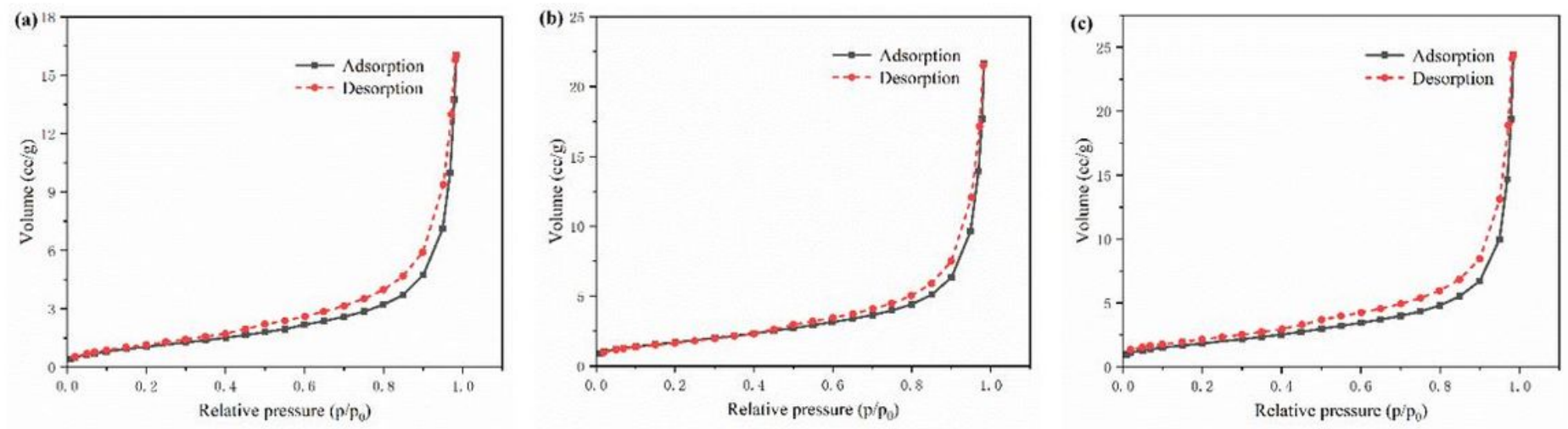

Figure 4

Adsorption and desorption isotherms of MOCM specimens with different HBSA content(a) $0 \%$;(b) $5 \%$;

(c) $10 \%$

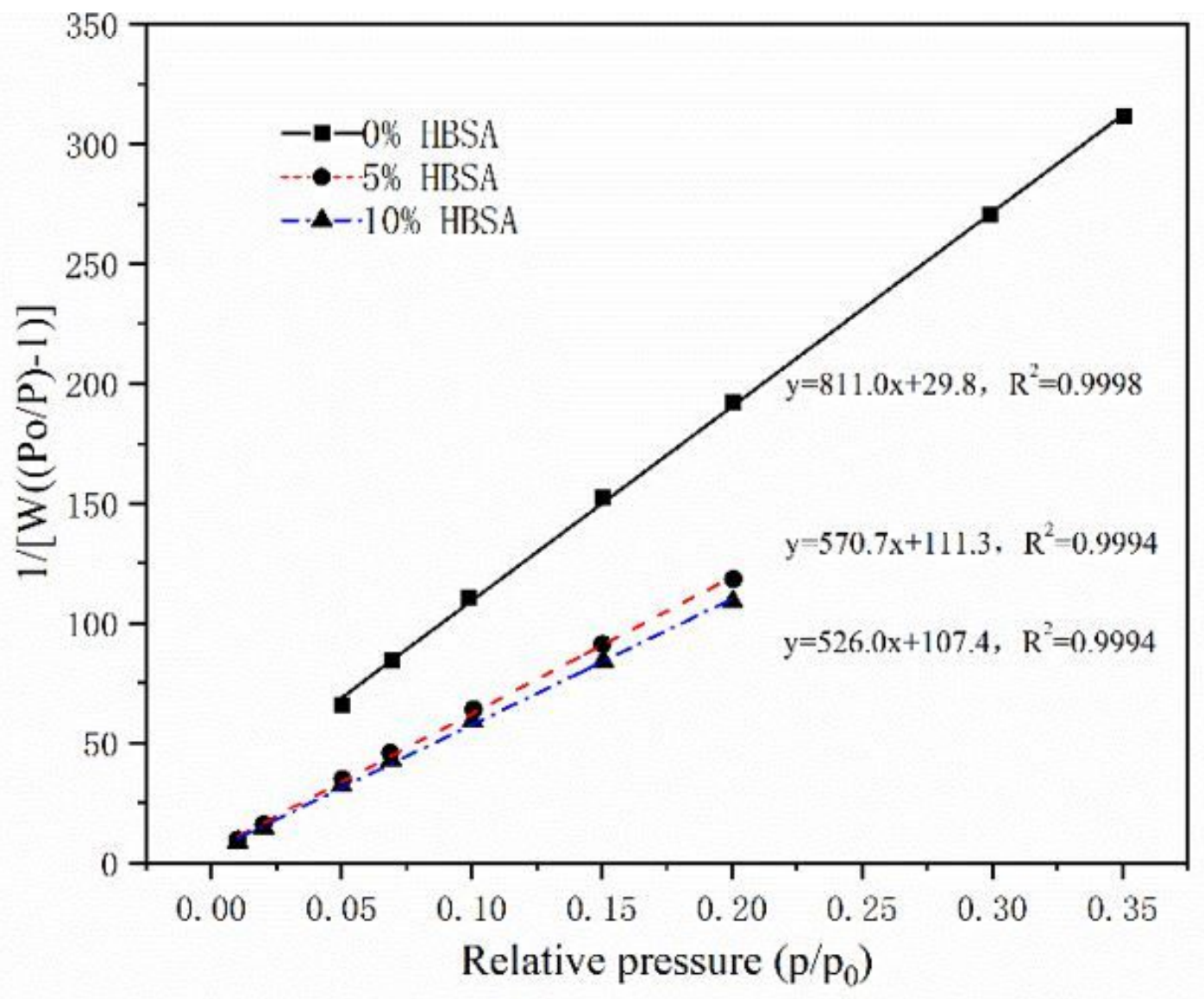

Figure 5 

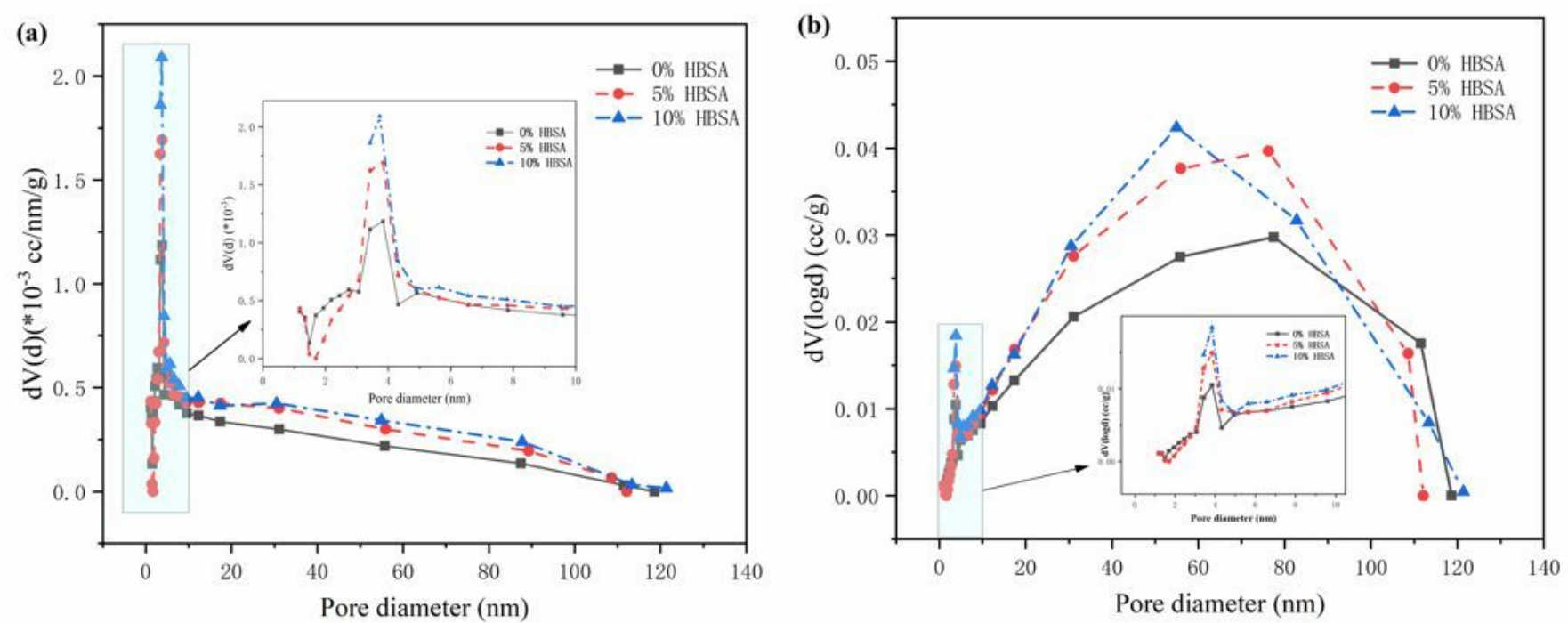

Figure 6

Pore diameter distribution of MOCM with different HBSA content(a)micropores;(b) mesoporous
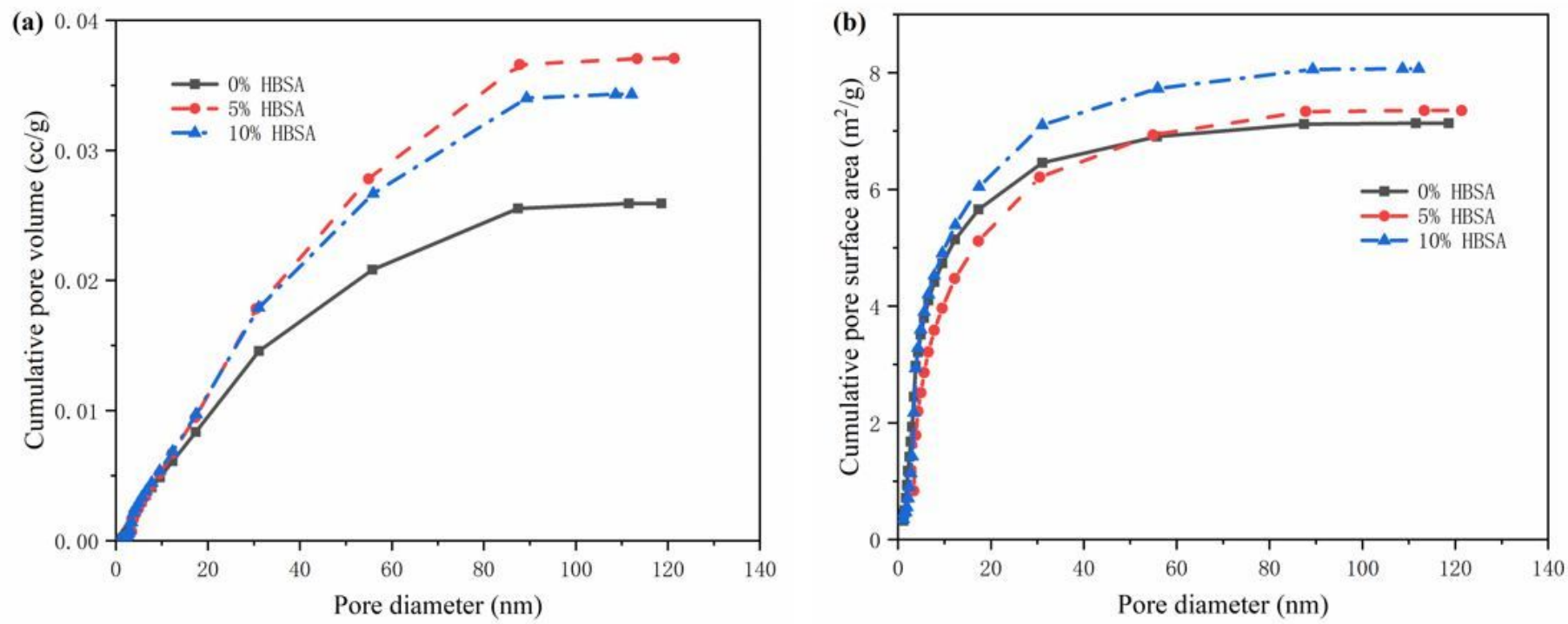

Figure 7

MOCM with different HBSA content for (a)cumulative pore volume; (b)cumulative pore surface area 
(a)

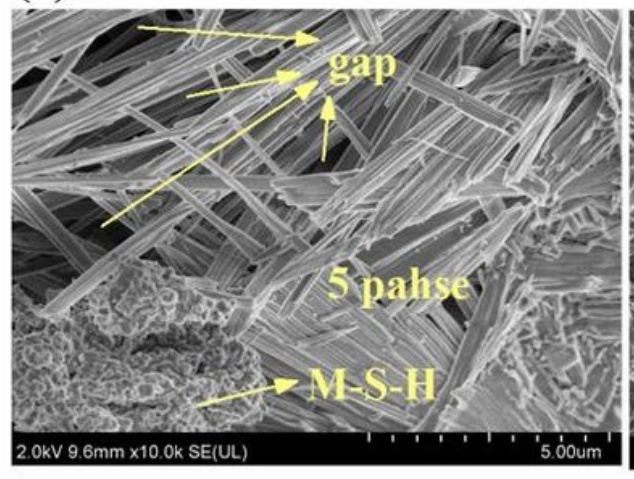

(b)

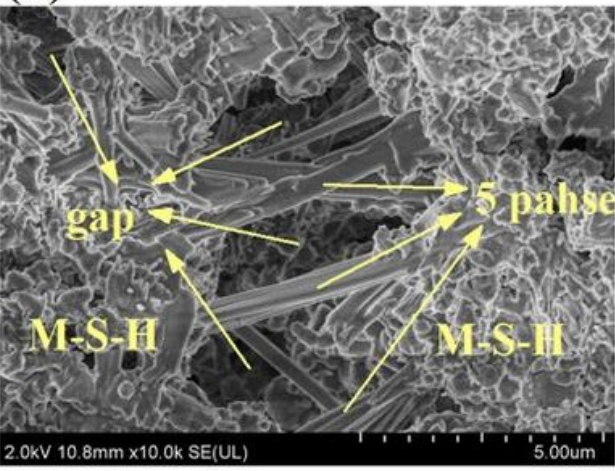

(c)

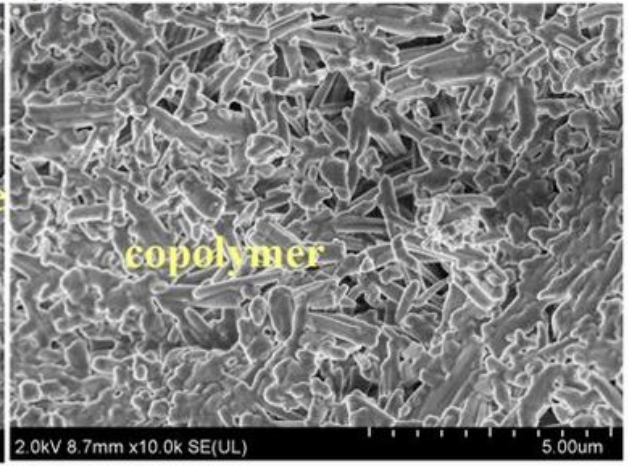

Figure 8

SEM of MOCM with different HBSA content (a) 0\%;(b) 5\%;(c)10\% 